\title{
Technological features of a combined soil processing machine and sprayer
}

\author{
Sergey K. Papusha*, Dmitry A. Kotov, and Valeria V. Zhadko \\ Federal State Budgetary Educational Institution of Higher Education «Kuban State Agrarian \\ University named after I.T. Trubilin» Krasnodar, Russia
}

\begin{abstract}
The combined unit is used for tillage with simultaneous introduction of protective and stimulating agents. A special feature of the unit is the use of pneumatic slot sprayers, they use a jet-forming device, which is necessary to create a highly dispersed air-drop jet. Agrotechnical requirements for such spraying ensure high quality distribution of the working fluid to the soil surface and supply the required rate of its consumption. The main task of the study of pneumatic slot sprayer was to determine the performance of this sprayer.
\end{abstract}

Increasing the productivity of agricultural machinery is the main direction in the development of agricultural production on the basis of complex mechanization of production.

Energy-saving technologies are the basis of intensification of technological processes when carrying out work in the field within the stipulated agrotechnical terms, which is possible by using combined units that perform several operations in one pass.

Integrated plant protection helps to increase economic efficiency in the cultivation of various crops.

The use of chemical and biological plant protection products and the promotion of crop growth occur at almost all stages of agricultural production.

The main method that uses a chemical method of plant protection is spraying, which is carried out for pre-emergence soil treatment in order to control weeds, pests, diseases and fertilizing plants in the process of their development. Along with this, it is necessary to etch the seed material with various fungicides, and to regulate growth, it is necessary to add biologics, microbiological and immune-stimulating agents.

The combined use of biologics and biologically active substances with pesticides will reduce the rate of consumption of pesticides by $20-30 \%$.

However, the use of biologics and effective microorganisms is limited, since they cannot be used as tank mixtures, and some microorganisms die when they are applied under the pressure created by many modern sprayers.

Given that the main method that uses chemical means of protection is spraying, that is, processing objects with liquid preparations, the recommended method for applying biological remedies is ultra-low-volume.

Since the process of crops cultivation begins with preparing the soil, it is proposed a

\footnotetext{
* Corresponding author: serega0318@mail.ru
} 
process of tillage by the combined unit, with simultaneous application of protectivestimulating means by the ultra-low-volume sprayer with pneumatic slotted nozzles designed in Kuban State Agrarian University to apply energy-saving technologies [1].

A special feature of pneumatic slot sprayers is the use of an air jet as a means of delivering drops of working fluid at a given speed and dispersing the working fluid with an optimal set drop diameter in accordance with agricultural requirements.

Pneumatic slotted sprayers designed in KubSAU to create a highly dispersed air-drop jet use a jet generator with a slotted nozzle with an upper or lower supply of working fluid to the jet outlet zone.

The device to the tillage tool for applying protective and stimulating liquids is installed on the frame of the harrow. Sprayers are fixed at an angle to the direction of movement of the unit with an overlap of air-drop jets and are isolated from the tractor and working bodies of the disk harrow by aprons (Fig. 1).

The technological process of the spraying device consists in the fact that the working fluid from the reservoir 1 is supplied to the feeders 4 through pipelines 3 through the equalizing tank 2. Compressed air is supplied from the compressor via pneumatic conduits to the spray jet to create an air jet from the slot nozzle for dispersion of the working fluid [2].

The air-drop jet treats the soil with appropriate preparations intended to saturate the soil with them in order to protect and stimulate the growth of plants during their cultivation.

Agrotechnical requirements for ultra-low volume spraying, provide for the supply of an appropriate rate of flow of the working fluid and a high quality of its distribution on the surface, which depends on the density of the surface coating and the size of drops (MMD = 150/200 microns).

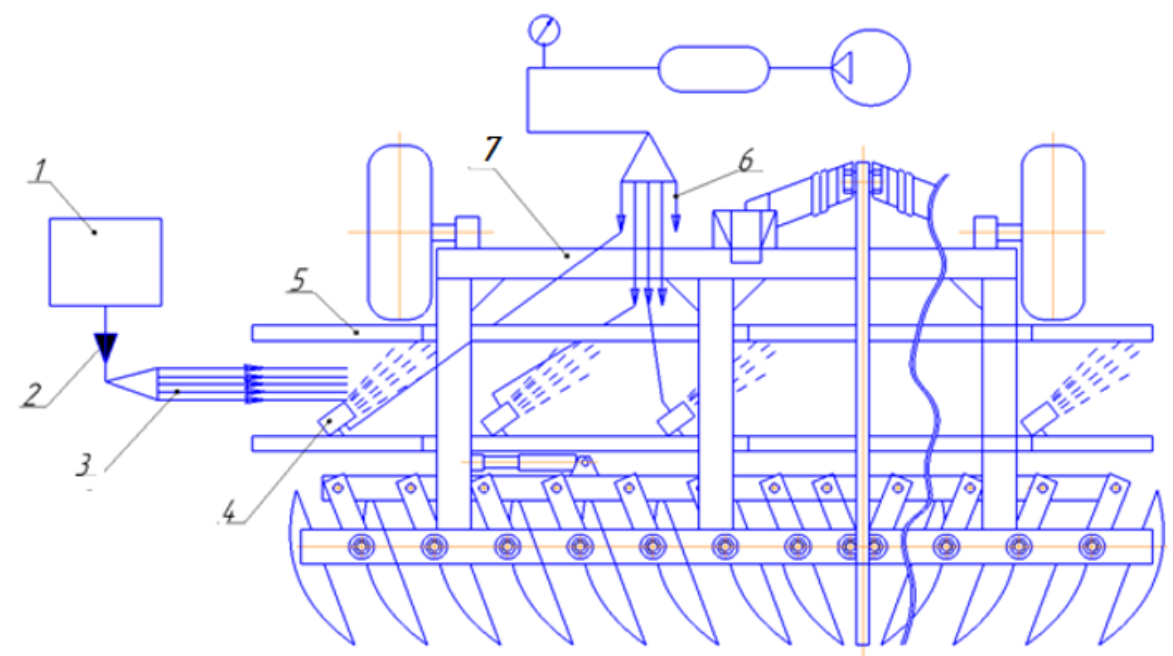

Fig. 1. Device for soil processing to introduce protective-stimulating liquid. 1. - tank; 2. - equalizing tank; 3. - pipelines; 4. - sprayers; 5. - aprons; 6. - air ducts; 7. - frame.

For small air-hydraulic sprayers, the formula (1) for calculating the average diameter of drops obtained empirically is applicable.

$$
d_{s}=\frac{585}{w-v} \cdot\left(\frac{\delta}{\rho}\right)^{0,5}+597 \times\left(\frac{\eta}{\sqrt{\delta \cdot \rho}}\right)^{0,45} \cdot\left(1000 \cdot \frac{Q_{w}}{Q_{v}}\right)(1)
$$


where $d_{s}$ - average volume-surface diameter of drops;

$w-v-$ air and liquid velocity, $\mathrm{m} / \mathrm{s}$

$\delta$ - surface tension of liquid, g/sm;

$\eta$ - viscosity of liquid, poise;

$\rho$ - density of liquid, $\mathrm{g} / \mathrm{sm}^{3}$;

$\frac{Q_{w}}{Q_{v}}$ - ratio of volume rates of liquid and air.

To calculate the speed of the air jet, the initial parameters of the sprayer were adopted: the liquid flow rate of $0.200 \mathrm{l} / \mathrm{min}$, the liquid density of $1.00 \mathrm{~g} / \mathrm{cm}^{3}$, and the surface tension coefficient $72,5-10^{-3} \mathrm{~g} / \mathrm{cm}$ and a liquid velocity of $0.20 \mathrm{~m} / \mathrm{s}$. The calculation results are shown in figure 2 .

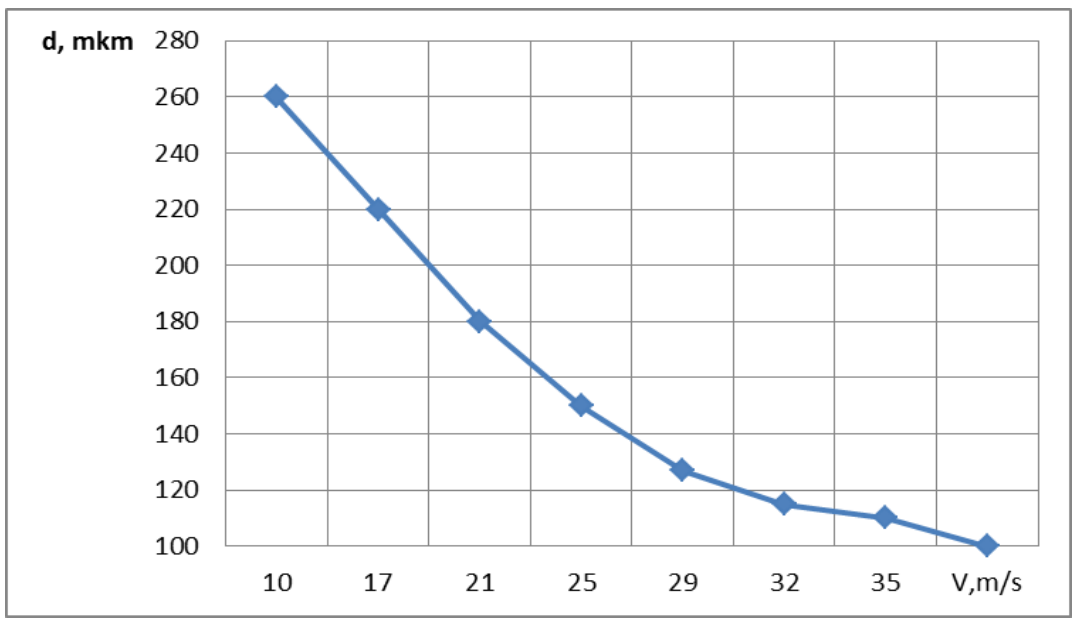

Fig. 2. Changing the size of droplets due to the speed of the air jet from the slot nozzle of the sprayer.

Thus, to obtain an air-drop jet with a drop diameter of 200 microns, it is necessary that the jet speed is $18-19 \mathrm{~m} / \mathrm{s}$.

One of the research tasks of a pneumatic slot sprayer is to determine the performance of a pneumatic slot sprayer.

Using the results of previous studies, the main design parameters of the sprayers were selected.

The slot nozzle of the jet generator had an exit hole with dimensions $\mathrm{a} * \mathrm{~b}=0.3 \mathrm{~mm} * 5$ $\mathrm{mm}$, and a tube-type feeder with an exit hole diameter of $3 \mathrm{~mm}$ [3].

We considered the supply of working fluid to the feeder from above and below relative to the axis of the slot nozzle.

For the study, the working fluid came from a 1-liter container installed on a platform with a rack. Below the tank, an equalizing tank with the ability to move along the height was fixed on the rack. A reference point was fixed on the rack for setting a definite height of the spray nozzle $h$ relative to the level of the working fluid in the equalizing tank. The sprayer is moved on the rack so that the center line of the slot nozzle of the sprayer coincides with the marks on the rack showing the necessary positions corresponding to the specified pressure $\mathrm{H}$ [4].

The tank was filled with water simulating the working fluid, and during the spraying process, after turning on the compressor, the time of water flow from the tank was determined. According to the obtained result of the temporary expiration of $100 \mathrm{ml}$ of water 
when fed from the corresponding levels, the flow rate of the working fluid $q_{m}$ was calculated. The results of the research are shown in figure 3.

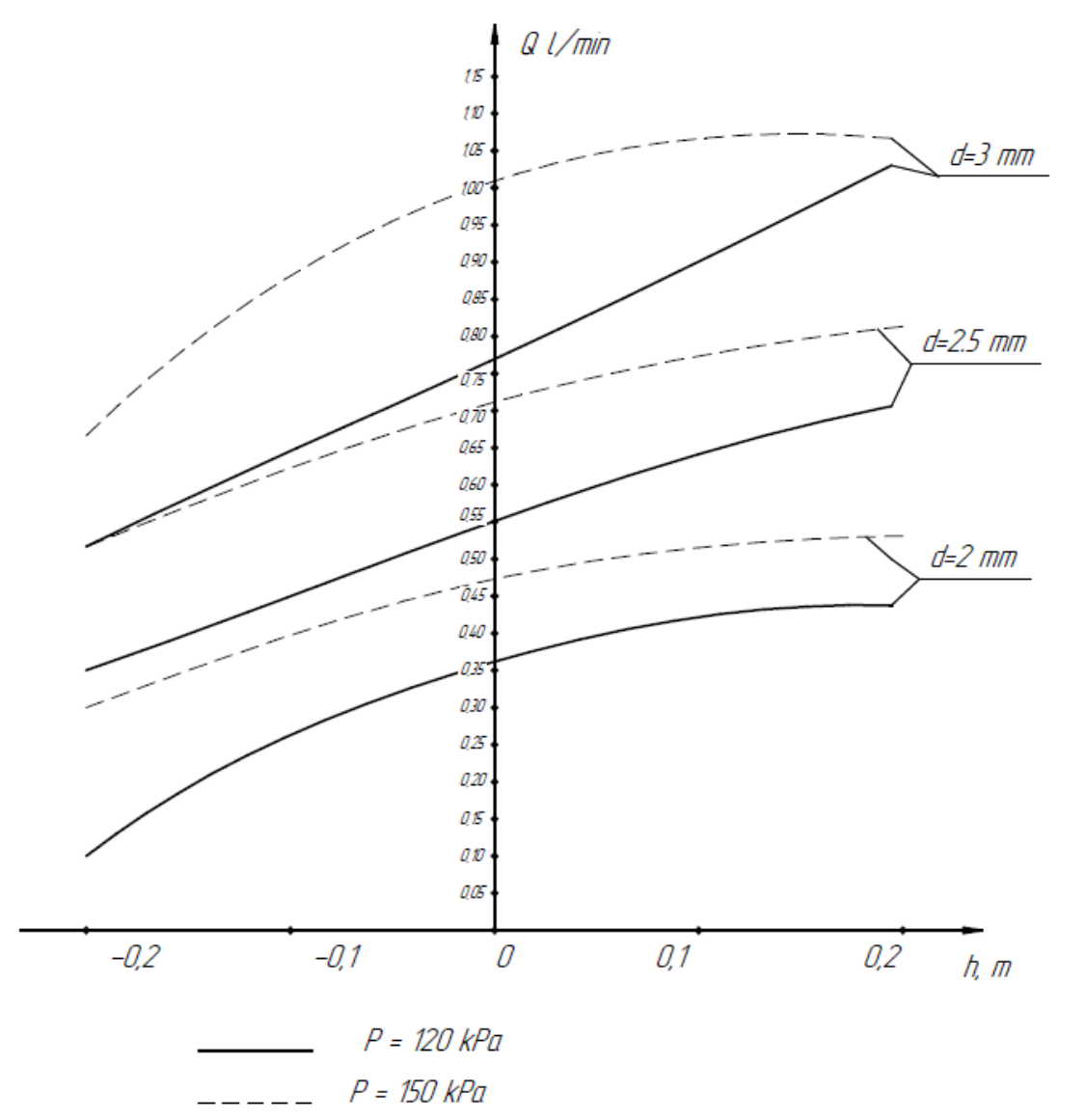

Fig. 3. Diagram of setting the pneumatic slot sprayer on the working fluid flow rate ( $g_{ж} 1 / \mathrm{min}$ )

To set the sprayers to the specified flow rate of the working fluid, calculate the flow rate of the working fluid using the formula:

$$
q_{\varkappa}=\frac{Q v B}{600 n} l / \mathrm{min}
$$

where $Q$ - consumption rate, l / ha;

$v$ - unit velocity, $\mathrm{km} / \mathrm{h}$;

$B$ - gripping width, m;

$n$ - the number of nozzles, PCs.

Parameters Q, v, and B are the initial parameters for the unit, which in our case is a disk tool with a device for applying liquid remedies to the soil surface. where

To set up pneumatic slot sprayers for $q_{ж}$, you can use the graph in Fig. 3. $q_{ж}=f(h, d)$,

$h$ - position of the equalizing tank, m;

$d$ - diameter of the feeder outlet, mm.

The process of setting up the atomizers is shown in Fig. 3 as a dotted line. 
So for applying $\mathrm{Q}=10 \mathrm{l} / \mathrm{ha}$ of working fluid, at the speed of the unit $\mathrm{v}=8 \mathrm{~km} / \mathrm{h}$ and the gripping width of the unit $\mathrm{B}=4.2 \mathrm{~m}$, the flow rate of the spray $\mathrm{q}_{ж}=0.14 \mathrm{l} / \mathrm{min}$ is required for the number of sprayers $n=4$ PCs.

Thus, the use of a device for ultra-low-volume application of working fluid using pneumatic slot sprayers is considered as an effective implementation of energy-saving technology for applying not only pesticides to the soil, but also effective biologics and microorganisms that can restore soil resources and activate the process of cultivating agricultural plants.

\section{References}

1. Patent 2132611, Russian Federation. Sprayer ultra-low volume [Text] / G. G. Maslov, S. M. Borisova, V. A. Nebavsky; applicant and patentee of Kuban State Agrarian University.

2. Jet ejector sprayer [Text] / G. G. Maslov, S. M. Borisova. Mechanization and electrification of agriculture. - 1994. - №7. - P. 8.

3. Patent 2322056, Russian Federation, IPC A01M 7/00. Ultra-low volume sprayer [Text] / S. M. Borisova, G. G. Maslov, E. I. Trubilin, V. V. Tsybulevsky, P. F. Evdokimov, A.V. Repa; applicant and patent holder Federal State Institution of Higher Professional Education "Kuban State Agrarian University". - \# 2006126496/12; declared 20.07.2006; published 20.04.2008. Bul.\# 11.

4. Patent 2683510, Russian Federation, Device for a tillage tool for making protective and stimulating liquids [Text] / S. M. Borisova, S. K. Papusha, R. A. Medvedev, N. A. Nikitenko, applicant and patent holder Federal State Institution of Higher Professional Education " Kuban State Agrarian University». 